\title{
Gender Differences in the Speech Events of Kurdistan Parliament
}

\author{
Dlveen Abdullah Sadiq \\ Department of English, College of Languages - Salahaddin University-Erbil, Kurdistan Region, \\ Iraq. \\ Email: dlveenabdullsattar@gmail.com
}

\section{Salam N. H. Hakeem}

Department of English, College of Education, Salahaddin University- Erbil, Kurdistan Region, Iraq.

Email: salam.hakeem@su.edu.krd

\begin{abstract}
:
This study tackles the differences between male and female MPs' language in Kurdistan Parliament and the reasons behind such differences. The study investigates the extent and the type of gender differences between male and female MPs in Kurdistan and how these differences may lead to misunderstandings while debating. . In addition, the study highlights the MPs' perspective on gender stereotypes and how such perspectives may affect their interactions. A quantitative method has been used to analyze the data of the study. First, an ethnographic description of Kurdistan Parliament according to Hymes's speaking framework was given, focusing on the setting, the participants and the act sequence. Second, a questionnaire was prepared as the data collection tool of the study. Based on the analysis of the collected data, it was found out that both male and female MPs strongly agreed that gender differences in language use could lead to misunderstandings. Moreover, MPs confirmed that the Kurdish society is patriarchal, and this leads to male dominance in most of the social interactions including parliamentary debates.
\end{abstract}

Keywords: gender differences, language, speech event, parliament, ethnography of speaking 


\section{Introduction:}

Language is the most important means of communication in one's society (Wardhaugh and Fuller, 2015: 2).people use language to express our emotions, ideas and needs. However, there are a number of factors that can affect a person's language, namely their gender, the education that they receive, their age and occupation, but gender might be the most significant one.

Men and women play different roles in the society in relation to their participation in social activities, and this is reflected in their languages. However, men and women with similar social backgrounds usually speak differently, and this difference involves such aspects as vocabulary, pitch, style, and grammatical conversations. In the Kurdistan parliament, male and female MPs sometimes perceive the same messages differently, and recognizing these differences in communication between male and female MPs will help them to avoid many political or personal misunderstandings when communicating with the opposite sex.

For this study, an ethnographic approach has been adopted to highlight the importance of experience, event, participants and culture. The main purpose of the study is to recognize the gender difference in using language and how such differences may affect the MPs' debates in Kurdistan parliament.

\section{Theoretical Framework:}

A historical background of language and gender in the form of literature review is provided below in addition to an ethnographic description of the Kurdistan Parliament Hymes's speech framework.

\subsection{Gender and Language:}

Research on gender in its early stages took for granted the binary sex categorization that divided men and women. Specifically, Sunderland and Litosseliti (2002) summarise early works as studies that considered the binary nature of sex as a sociolinguistic variable, whose results as well as their understanding of gender, "impl[ied] fixedness" (Sunderland \& Litosseliti, 2002, p. 4, their emphasis). In critiquing early work on language in relation to sex, Coates (1989) described them to be quantitative counting of apparently different features in language use between male and female speakers, as a reflection of speaker's sex. Relatedly, Wodak (1997) warned that studies on gender 
variation (which started with Labov in the 60s) had too often neglected variation among groups of men or of women.

Language and gender have been linked in history before the second wave of Women's Movement began in late 1960 and early 1970s.Back to the early era before 1960 and 1970 there was a preliminary understanding of gender and language but the studies were not tackled academically.In fact, there were old sayings, explained below, that represented women's use of language negatively due to certain social and cultural beliefs (Sunderland, 2006, p.3):

Three women make a market. (English)

Women are nine-times more talkative than men. (Hebrew)

Consult a woman, but don't do what she says. (Kurdish)

William Labov's and Peter Trudgill's study had great impact on the study of language and gender. In his study in urban British English of Norwich, Trudgill found out that women tended to use more prestigious forms than men. He also found out that women were more status-conscious than men and they were aware that language plays an important role in that respect. Gender and language studies in the 1960s, the 1970s, and the 1980s have focused almost exclusively on women's language, rather than men's. This can be seen as an understandable and necessary response to the sustained historical exclusion of women in a patriarchal world order in general. Lakoff was the first monograph 'complete book' on language and gender. She established something called Women Language (WL), which is characterized by ten linguistic forms or features cited in (Holmes, 2006: 314).

- Lexical hedges or fillers, e.g. you know, sort of.

- Tag questions, e.g. she is very nice, isn't she?

- Rising intonation on declarative, e.g. it's really good

- Empty adjectives, e.g. divine, charming, cute.

- Precise colour terms, e.g. magenta, aquamarine.

- Intensifiers such as just and so.

- Hypercorrect grammar, e.g. consistent use of standard verb forms.

- Super polite forms, e.g. indirect requests, euphemisms.

- Avoidance of strong swearwords, e.g. fudge, my goodness.

- Emphatic stress, e.g. it was a BRILLIANT performance

Robin Lakoff 1957 has distinguished between three kinds of approaches in study of language and gender: deficit, dominance and difference. Each of these approaches has its own effect on language and gender. The deficit 
approach argued that male language is stronger and more desirable than female (Coates, 2013). According to Dominance model, linguistic differences between men and women are prompted by inequitable power relation between these two sexes.Different approaches views men and women as belonging to two equally valid but different sub-cultures due to the fact that they are socialized differently from childhood (Holmes, 2006).

\subsection{Gender and Sex}

The terms sex and gender have been used interchangeably sometimes as synonyms. However, theories of language and gender made a distinction between sex and gender as biological and cultural constructs, respectively (Kiesling 2019). Sex refers to the biological difference between men and women, while gender is a term used to describe socially constructed categories based on sex or binary division of humans (Coates, 2013: 38).

Gender is a lot more than individual biology. It involves certain attributes that are socially attached to men and women. Gender is an ideological system, and ideology is a shared conceptual system for organizing the world. That is, we imagine the world in which there are masculinity and femininity. Color might be a good example; that blue is for masculinity and pink for femininity (Kisling, 2019: 24). Sex is biologically constructed and gender is culturally constructed. This is not always completely clear because between male and female there are additional cultural specific categories that define people. As this is called transgender and it is often used in the United States to talk about people who are transitioning or have transitioned from one sex category to another, or have biological attributes of a sex category that do not match their gender (Eckert and Ginet,2003).

\subsection{Ethnography of Speaking by Dell Hymes:}

Ethnography of speaking was founded in 1960 by Dell Hymes for understanding language, but later it became to be ethnography of communication. Ethnography of communication is the study of communication within the background of the social and, cultural beliefs. Hymes proposed this method to study and analyze communicative behavior. He argued that there are particular components of speech events that can be divided into eight groups, referred to a speaking grid. These components are the setting, physical location; the participants, speaker addressees and the audience; the ends, shared goals; the act, content and sequential agreement; the key, tone and manner of speaking, hummer or serious; the instrumental form and style of speaking; the norm, social rules leading event; the genres, kind of speech casual or poetry (Spolsky, 2004: 62).

\subsubsection{Setting:}


The setting is the physical circumstance of the communicative event including time and place. Scene is the "psychological setting" or "cultural definition" of a scene including characteristics such as range of formality and sense of play or seriousness (Hymes, 1974: 55-56).

The setting of speech events in the Kurdistan parliament is the main hall, which is located in the Parliament. The seats are arranged in a way that all members are seated in a semicircle shape. In front of them, there is a dais with three chairs for parliament presidency, deputy speaker and secretary. It is designed to be the highest point in the hall in order to reflect the absolute authority of the speakers so they can face the members below the presidency chair, which is a place for committees to participate during debates that related to the legislation. The scene of Kurdistan parliament is usually formal and serious.

\subsubsection{Participants:}

The element $\mathrm{P}$ in Hymn's model of speaking represents participants in the communicative process and the relationship among them. Hymn proposes four different roles addressor, speaker, addressee, and hearer, but he stated that conversations may require only two roles 'addressor and addressee' where others may require speaking or listening on behalf of other (Hymes, 1974: 62). The Participants in Kurdistan Parliament are the MPs, president and the secretary of president. All participants have formal relations.

\subsubsection{Ends:}

Ends of speech events can be divided into two separate types: the goal of the speech and the outcome (Hymes, 1974: 65). The main purposes of the parliamentary sessions are representing people's view, making law, authorizing the government institutions, debating major issues, allocating the regional budget, policing, natural resources management, and infrastructure development.

\subsubsection{Act Sequence:}

Act sequences involve form and content. Hymes states that act sequences are message-form and message-content structures. The message does not mean dialect or variety, but it rather means the speech style. For example, how much directness is expected and is the message direct or indirect (Hymes, 1974: 55).

MPs in Kurdistan parliament usually deliver their messages in direct form in order to give clear views on the issues. 


\subsubsection{Key:}

The key is defined as the tone or manner in which an act is performed. It means an overall tone or manner. For example the tone can be serious, joyful or angry (Coulthard, 1985: 48).

The overall tone of the discussion of the Parliamentary debates in Kurdistan is serious. Sometimes this serious tone changes to anger due to the pressure, different perspectives and conflict between political parties.

\subsubsection{Instrument:}

Instrument refers to the channel of communication; which may take the form of oral face-to-face communication, written in the form of a report, telegraphic or semaphore (Paulston et al, 2012: 78).

The channel in the parliament is oral because all MPs are speaking face to face. However, parliamentary debates in Kurdistan have also acquired written form because reports have been written by MPs to clarify certain issues.

\subsubsection{Norm:}

Hymes distinguished between two aspects of norm. The first is the norm of interaction, which is simply the "Rule" of how speakers supposed to behave in ideal speech event, who should talk, and when the turn should change. The second aspect is the norm of interpretation, which depends on the history, ideologies, and practices shared in a culture (Gumperz and Hymes, 1991: 98).

The rules in Parliament in Kurdistan have been written in Rules of Procedure that are distributed among MPs. The Rule of Procedure describes the rights and duties of MPs and the deportments that are not allowed. For example, the president of parliament of Kurdistan has full authority and all MPs address their comments to the president and he selects who to speak first.

\subsubsection{Genre:}

The final component is that of genre, which Hymes describes as 'the patterns of sonnets, sermons, poem, myth, tale, proverb, riddle, curse, prayer, oration, lecture, commercial, and any other organized routines and styles" the kind of speech act or event. It refers to the type of form delivery. These terms can be applied to many kinds of discourse. Sometimes in a written discussion you might emphasize only two or three of the letters of the mnemonic. It provides a structure for you to perceive components (Wardhaugh, 2010: 261).

\subsection{The Research Questions}

The study attempts to find answers for the following questions: 
1. Are there gender differences in the language that MPs use during parliamentary sessions?

2. Do this gender differences leads to misunderstanding?

3. To what extent are male and female MPs aware of their gender differences?

4. What linguistic aspects are noticeably different?

\subsection{The Aims of the Study}

The present study aims at the following:

1- Investigating the effect of gender differences on the language of MPs in Kurdistan.

2- Identifying MPs' perspectives on gender differences.

3- Identifying MPs' views on most common gender stereotypes that are common in the society.

4- Investigating male and female MP's speech style while debating.

\subsection{Methodology and Data Collection:}

This empirical study uses a quantitative method to analyse the collected data.To achieve the aims of the study, a questionnaire has been prepared by the researcher to identify the MPs' perspectives in relation to the study. The

study sample is the $5^{\text {th }}$ term of Parliamentary debates in 2018, which took place in Kurdistan on 30 September 2018. The election involved hundreds of candidates vying for the 111 seats in the Regional Parliament, including five allocated ones for Turkmen, five for Christians and one for the Armenians. About 3085461 people were eligible to vote in Kurdistan, and 1845979 people voted. The percentage of people's participation in the election was $59 \%$. The 111 parliamentary seats were contested by 21 parties.

\subsection{Data Analysis and Discussion:}

The questionnaire has been carefully analyzed to identify MPs' views on gender differences. The questionnaire includes two sections. The first section is general information about MPs' education gender, position and experience. The second section is nineteen questions that have been discussed and analyzed using SPSS statistics method to accomplish research objectives. The aim of the questionnaire in the present work is to collect data in order to answer the research questions and to explore the influence of gender in language use in parliamentary debates. 


\section{Question (1)}

During mixed-gender conversations, do you notice that there are differences between male and female MPs' language?

Table 1.1: Differences between male and female MPs' language

\begin{tabular}{|c|c|c|c|c|c|c|}
\hline \multirow{2}{*}{ Response } & \multicolumn{2}{|c|}{ Male } & \multicolumn{2}{c|}{ Female } & \multicolumn{2}{c|}{ Total } \\
\cline { 2 - 7 } & Frequency & Rate (\%) & Frequency & Rate (\%) & Frequency & $\begin{array}{c}\text { Rate } \\
(\%)\end{array}$ \\
\hline Yes & 45 & 71 & 22 & 81 & 67 & 74 \\
\hline No & 18 & 29 & 5 & 19 & 23 & 26 \\
\hline Total & 63 & 100 & 27 & 100 & 90 & 100 \\
\hline
\end{tabular}

The first question focuses on the speech differences that both genders notice when speaking with each other. Table 1.1 shows that out of 63 male MPs, 45 of them said yes and only 18 said no. However, the analyzed data illustrates that $71 \%$ of male MPs realized the differences in their speech during their conversation. Concerning female MPs, 22 of them said yes and 5 of them said no, while $81 \%$ of females believe there is a difference between males and females speeches, but the remaining 19\% do not feel any alteration in language use during mixed-gender conversations. It can be deduced from the data results that the female MPs are more aware of the gender differences than the males.

\section{Question (2)}

Do you notice if this gender difference leads to misunderstanding? If yes, why?

Table 1.2: Gender difference leads to misunderstanding

\begin{tabular}{|c|c|c|c|c|c|c|}
\hline \multirow{2}{*}{ Response } & \multicolumn{2}{|c|}{ Male } & \multicolumn{2}{c|}{ Female } & \multicolumn{2}{c|}{ Total } \\
\cline { 2 - 7 } & Frequency & Rate (\%) & Frequency & Rate (\%) & Frequency & Rate (\%) \\
\hline Yes & 39 & 62 & 20 & 74 & 59 & 66 \\
\hline No & 24 & 38 & 7 & 26 & 31 & 34 \\
\hline Total & 63 & 100 & 27 & 100 & 90 & 100 \\
\hline
\end{tabular}

Table1.2 represents MPs opinion on the second question of the questionnaire, $66 \%$ of both male MPs and female MPs strongly agreed that the difference leads to misunderstandings. Coincides with Tannin's study in 1990 argued that women speak and hear a language of connection and intimacy, while men speak and hear a language of status and independence, a difference that makes communication between the sexes in workplace problematic. He also 
adds that "communication between men and women can be like cross cultural communication, prey to a clash of conversational styles" (Spolsky, 2004, p. 4).

However, in response to the second part of the question, many MPs stated that this misunderstanding was due to the fact that the parliament includes many political parts and this diversity leads to misunderstanding, not gender itself. On the other hand MPs seem to be aware of their differences but they do not understand the real reason behind these differences, it might be biological or cultural difference. Female MPs are more aware of their misunderstanding than male MPs because $74 \%$ of MPs said yes and only $26 \%$ said no.

\section{Question (3)}

In your conversation, do you often use tag questions like, isn't it, don't you?

Table 1.3: Distribution of respondents by using tag questions

\begin{tabular}{|c|c|c|c|c|c|c|}
\hline \multirow{2}{*}{ Response } & \multicolumn{2}{|c|}{ Male } & \multicolumn{2}{c|}{ Female } & \multicolumn{2}{c|}{ Total } \\
\cline { 2 - 7 } & Frequency & Rate (\%) & Frequency & Rate (\%) & Frequency & Rate (\%) \\
\hline Yes & 56 & 89 & 19 & 70 & 75 & 83 \\
\hline No & 7 & 11 & 8 & 30 & 15 & 17 \\
\hline Sum & 63 & 100 & 27 & 100 & 90 & 100 \\
\hline
\end{tabular}

It can be noticed that $89 \%$ of male MPs use tag questions while $70 \%$ of female MPs use them during parliamentary debates in Kurdistan. Lakoff argued that tag questions are associated with the desire of approval which is a signal for the speaker's lack of self-confidence, and it is more often used by women. However, in the parliament the rate of using tag questions by male MPs is higher than that used by female MPs. There are two possible interpretations for this higher rate. First, it can be suggested that tag questions are used to manage the flow of conversation. Second, it seems that male MPs tend to use affective tag questions to show that they are in control of conversation, and this might indicate that male MPs are more powerful.

\section{Question (4)}

Do you notice that Male MPs raise their voices during debates to try to prove their point? If yes why?

Table 1.4: Male MPs raise their voices during debates

\begin{tabular}{|l|l|l|l|l|l|l|}
\hline \multirow{2}{*}{ Response } & \multicolumn{2}{|c|}{ Male } & \multicolumn{2}{c|}{ Female } & \multicolumn{2}{c|}{ Total } \\
\cline { 2 - 6 } & Frequency & Rate (\%) & Frequency & Rate (\%) & Frequency & Rate (\%) \\
\hline
\end{tabular}




\begin{tabular}{|c|c|c|c|c|c|c|} 
Yes & 48 & 76 & 19 & 70 & 67 & 74 \\
\hline No & 15 & 24 & 8 & 30 & 23 & 26 \\
\hline Sum & 63 & 100 & 27 & 100 & 90 & 100 \\
\hline
\end{tabular}

In table 1.4 one can see that $74 \%$ of the total MPs think that male talk loudly while debating. Among them 48 are male and 19 are female MPs. It is important to highlight that most male MPs realized they talk loudly while debating. This indicated that male wanted to show their manhood and supremacy. One of the male MPs said "it is our nature" which implies that biology affects this gender difference between men and women since men have low pitch and bigger vocal. An interesting response by one of the male MPs to the second part of the question was "Because we live in a patriarchal society". This highlights the fact that male MPs are aware that the Kurdish society is a patriarchal and they admit that they raise their voices because it is part of the Kurdish culture for men to have strong assertive voices, while women usually talk quietly, which is evidently reflected in their parliamentary debates in Kurdistan.

\section{Question (5)}

Do you notice that female MPs use expressions like: I think" "in my opinion" more than men?

Table 1.5: Female MPs use expressions like: I think" "in my opinion" more than male MPs

\begin{tabular}{|c|c|c|c|c|c|c|}
\hline \multirow{2}{*}{ Response } & \multicolumn{2}{|c|}{ Male } & \multicolumn{2}{c|}{ Female } & \multicolumn{2}{c|}{ Total } \\
\cline { 2 - 7 } & Frequency & Rate (\%) & Frequency & Rate (\%) & Frequency & Rate (\%) \\
\hline Yes & 52 & 83 & 17 & 63 & 69 & 77 \\
\hline No & 11 & 17 & 10 & 37 & 21 & 23 \\
\hline Sum & 63 & 100 & 27 & 100 & 90 & 100 \\
\hline
\end{tabular}

In table 1.5 one can see that most of the participants claimed that women use expressions like "I think, in my opinion", which possibly denotes uncertainty in women's language. Among them 83\% are male MPs and 69\% are females. However a popular explanation for this was stated by Lakoff in 1975 who published an influential account of women's language in her book which is entitled "Language and Woman's Place". She mentioned a set of basic assumptions about what marks the language of women. Among them the overuse of qualifiers and hedges, she argued that women usually lack power and have low social status. However, in Kurdistan Parliament some female MPs have high position with absolute power but still overuse qualifiers. According to the responses $63 \%$ female 
MPs believe that they use such expressions because they are uncertain. This has the social and cultural implication that even after putting women in high positions,they lack confidence. On the other hand, Kurdish society is patriarchal, so it gives supremacy to men who are responsible for making important decisions and this makes women feel less confident.

\section{Question (6)}

Do you think that male MPs are more dominant in debates?

Table 1.6: Distribution of respondents by thinks that male MPs are more dominant in debates.

\begin{tabular}{|c|c|c|c|c|c|c|}
\hline \multirow{2}{*}{ Response } & \multicolumn{2}{|c|}{ Male } & \multicolumn{2}{c|}{ Female } & \multicolumn{2}{c|}{ Total } \\
\cline { 2 - 7 } & Frequency & Rate (\%) & Frequency & Rate (\%) & Frequency & Rate (\%) \\
\hline Yes & 5 & 8 & 24 & 89 & 29 & 32 \\
\hline No & 58 & 92 & 3 & 11 & 61 & 68 \\
\hline Sum & 63 & 100 & 27 & 100 & 90 & 100 \\
\hline
\end{tabular}

Table 1.6 illustrates participants' perspectives on male MPs' dominance in debates. Most male MPs seems to do not agree that male MPs are dominant while debating however, female MPs agreed that male MPs are dominant, among female MPs $89 \%$ of them said yes only $24 \%$ said no. On the other hand among male MPs $92 \%$ of the believed male MPs are not dominant while only $8 \%$ assumed they are dominant this result revealed that male MPs do not realize their supremacy and dominance. In contrast to the study by West and Zimmerman; they argued that men tend to be more dominant in conversation (Maltz, and Borker, 2006).

The dominant approach lacks the complexity of power and only focuses on the male dominance. For example, in the parliament some female MPs have significant positions and they are commissioner in parliament, so this power difference might affect the relation between male and female MPs and female MPs who might become more dominate than male.

\section{Question (7)}

Do you notice that male MPs tend to interrupt female MPs?

Table 1.7: Distribution of respondents whether male MPs tend to interrupt female MPs.

\begin{tabular}{|l|l|l|l|}
\hline Response & Male & Female & Total \\
\hline
\end{tabular}




\begin{tabular}{|c|c|c|c|c|c|c|}
\hline & Frequency & Rate (\%) & Frequency & Rate (\%) & Frequency & Rate (\%) \\
\hline Yes & 4 & 6 & 4 & 15 & 8 & 9 \\
\hline No & 59 & 94 & 23 & 85 & 82 & 91 \\
\hline Sum & 63 & 100 & 27 & 100 & 90 & 100 \\
\hline
\end{tabular}

Table 1.7 shows that $94 \%$ of male MPs thought that they do not interrupt female MPs. On the other hand, $82 \%$ of female MPs thought that male MPs do not interrupt female MPs while debating. One of the reasons behind the high percentage of 'No' in the question is that all MPs have their own time to speak and no one is allowed to interrupt other MPs except the president of the parliament who has full authority to interrupt MPs while organizing the sessions. Overall, these findings are in disagreement with findings reported by Dominance theory, which states that in mixed-sex conversations, men of tented to interrupt while debating (Sohn, 2006).

\subsection{Conclusions}

In conclusion, this study aimed to find out the effect of gender on MPs' language while debating in Kurdistan parliament, and whether this diversity between male and female MPs affects the process of interacting in Parliament. As the analyzed data above illustrates, male and female MPs are aware of their gender differences in the use of language. Both male and female MPs strongly agreed that these differences could lead to misunderstandings. This article obtained highly relative results proving that male MPs were aware of the fact that they raise their voices while debating. Male and female MPs confirmed that the Kurdish society is patriarchal, and this leads to male dominance in most of the social interactions including parliamentary debates. Another important finding was that both male and female MPs do not interrupt each other due to the formal setting in the parliament.

\subsection{Recommendations}

There are various steps that can be taken by government and individuals to eliminate the gender discrimination through raising the awareness of the society. The government has the responsibility to ensure equal representation of men and women in society, and the following points should be taken in consideration by the government and individuals:

1. Government should establish education system gender sensitive, including textbooks that promote gender equality and positive gender stereotypes. 
2. Providing development courses and seminars for teachers by professional trainers to promote gender equality.

3. Empowering women and girls by providing good system of education. Most of the Kurdish women especially in the countryside do not have access to education or technology that would improve their quality of life to adopt social and economic changes.

4. Promoting women's participation in policy, governance and electoral processes at all levels, in addition empowering girls' and women's organizations along with human rights defenders

5. Individuals can also do a lot to promote gender equality. Parents have a great influence in educating their children to create a healthy society for both genders. They should treat boys and girls in the same ways.

6. Creating gender equality in the media. Media has a great role in shaping the society and promoting social values; therefore government should guide the media to include gender issues in the news, and promote female leadership positions as a tool for positive change.

\section{يوخته:}

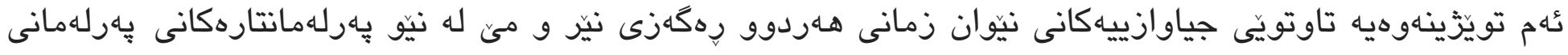

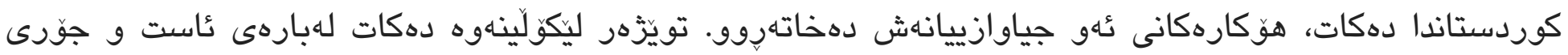

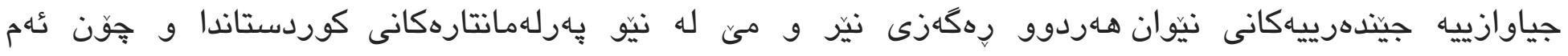

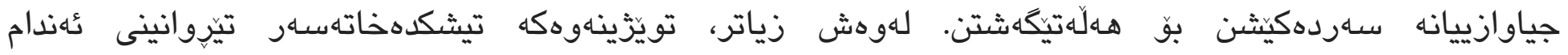

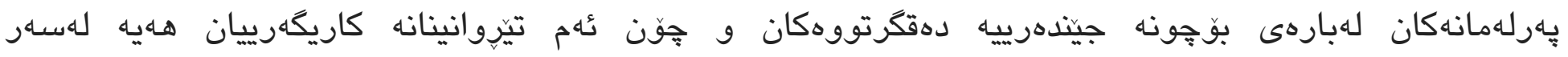

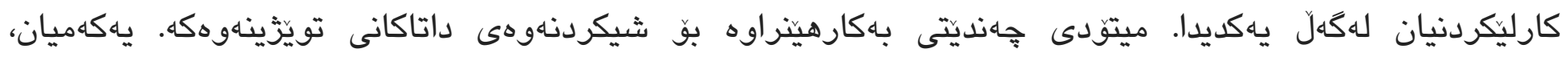

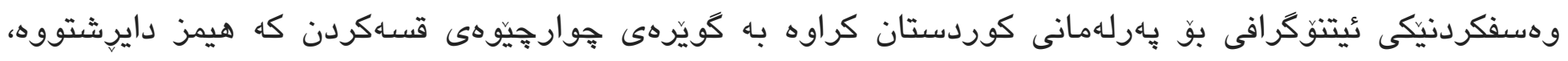

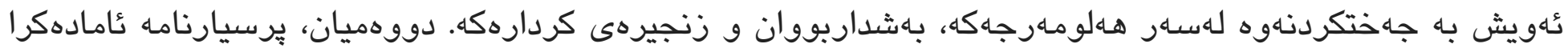

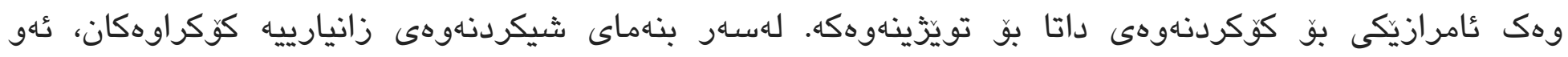

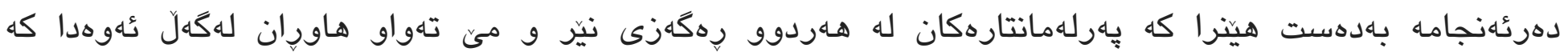

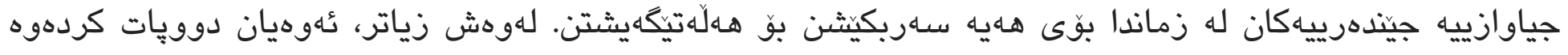




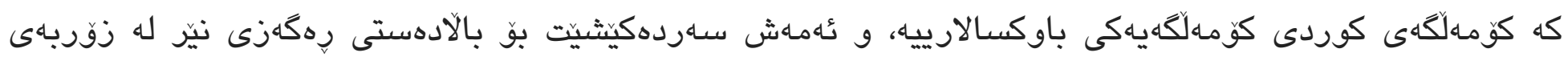

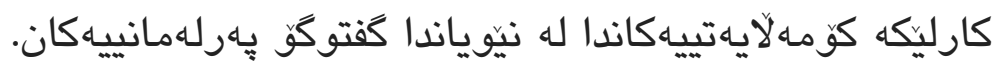

\section{ملخفص:}

تناول هذه الدراسة الاختلافات بين لغة أعضاء البرلمان من الذكور والإناث في البرلمان الكردستاني والأسباب الكامنة وراء هذه الاختلافات. تبحث الدراسة في مدى ونوع اختلافات الجنسين بين نائبين أناث وذكور في كردستان وكيف يمكن أن تتؤدي هذه الاختلافات إلى سوء فهم. بالإضافة إلى ذلك ، تسلط الدراسة الضوء على وجهة نظر النواب حول السلوك الجنسانية وكيف يمكن أن تؤثر هذه المنظورات على تفاعلاتهم. تم استخدام طريقة كمية لتحليل بيانات الدراسة. أولا، تم تقديم وصف إثنوغرافي للبرلمان الكردستاني وفقًا لإطار عمل هايمز، مع التركيز على الإعداد والمشاركين وتتابع الفعل ثانياً ، تم إعداد استبيان كأداة لجمع البيانات من الدراسة. بناء على تحليل البيانات التي تم جمعها، توصلت الدراسة إلى أن أعضاء البرلمان من الذكور والإناث وافقوا بشدة على أن الاختلافات بين الجنسين في استخدام اللغة يمكن أن تؤدي إلى سوء فهم. علاوة على ذلك، أكدوا أن المجتمع الكردي هو نظام أبوي، وهذا يؤدي إلى هيمنة الذكور في معظم التفاعلات الاجتماعية بما في ذلك المناقشات البرلماني.

\subsection{References:}

Coates, J. (2013). Women men and Language: a Sociolinguistic Account of

Gender Differences in Language, Oxon: Routledge.

Gumperz .J, and Hymes D., (1991) (eds.), Directions in Sociolinguistics: The

Ethnography of Communication, New York: Basil Blackwell.

Eckert, P., \& McConnell-Ginet, S. (2003). Language and Gender. Cambridge:

Cambridge University Press 
Hokmes, J. and Meyerhof, M. (2003). The Handbook of Language and Gender. Oxford: Oxford University Press. (2006). Gendered Talk at Work: Constructing Gender Identity through Workplace Discourse. Oxford: Blackwell. Hymes, D. (1974). Ways of speaking, in R. Bauman \& J. Sherzer (eds.), Explorations in the Ethnography of Speaking

Jespersen, O. (1992).Language; It is Nature, Development and Origin. London: George Allen and Unwin. Kiesling, S., (2019). Langue, Gender and Sexuality, New York: Rutledge.

Kurdistan of Parliament Federal Republic of Iraq: Role and Procedures of the Kurdistan Parliament. [ONLINE] available at https://www.parliament.krd/english/about-parliament/role-and-procedures/ [Accessed 6 Jun , 2019]

Maltz, D. N. and Borker, R. A. (2006). "A Cultural Approach to Male-Female Miscommunication".In Language and social Identity, edited by John J. Gumperz. Cambridge University Press Paulston, C., Kiesling, S. and Rangel, E. (2012).The Handbook of Intercultural Discourse and Communication. Malden: Blackwell.

Spolsky, B., (2004) Sociolinguistics. Oxford: Oxford University Press.

The Kurdistan Regional Government: The Kurdistan Parliament.2017. [ONLINE] available at http://previous.cabinet.gov.krd/p/page.aspx?1=12\&p=229[Accessed 21 August 2019].

Sunderland, J. (2006). Gendered Discourses. London: Palgrave-Macmillan.

Tannen, D (2004). You Just don't Understand: Women and Men in Conversation, $7^{\text {th }}$ ed.New York: William Morrow

Wardhaugh, R. 2010. An Introduction to Sociolinguistics, $6^{\text {th }}$ ed. Oxford: Wiley-Blackwell. 